\title{
Identification of a suitable qPCR reference gene in metastatic clear cell renal cell carcinoma
}

\author{
Piotr M. Wierzbicki • Jakub Klacz • Agnieszka Rybarczyk • Tomasz Slebioda • \\ Marcin Stanislawowski • Agata Wronska • Anna Kowalczyk • Marcin Matuszewski • \\ Zbigniew Kmiec
}

Received: 18 June 2014 / Accepted: 27 August 2014 / Published online: 16 September 2014

(C) The Author(s) 2014. This article is published with open access at Springerlink.com

\begin{abstract}
There is no data on reference gene (RG) selection in metastatic clear-cell renal cell carcinoma (mccRCC) for quantitative PCR (qPCR) data normalization. We aimed at selecting the most stable RG for further determination of new prognostic markers. Thirty-five nonmetastatic and 35 mccRCC patients undergoing radical nephrectomy were included. Paired primary tumor (T, $n=70)$ and normal (C, $n=70)$ kidney fragments were collected; from 12 out of 35 mccRCC cases, we also collected metastasized regional lymph nodes and adrenal gland tissues (M, $n=12)$. After RNA extraction, reverse transcription and qPCR were performed. Samples were divided into four analyzed groups. Fifteen candidate RGs were tested by RefFinder tool and manual statistics. To present the importance of RG selection, TP53 gene expression levels in samples were normalized with the use of RG data. $R P L 13$ gene was the most stable $\mathrm{RG}$ in analysis of 35 primary tumor nonmetastatic versus 35 mccRCC samples and matched metastasized T/C/M samples ( $n=12$, each group). GUSB was the most suitable RG in total 152 samples and in paired $\mathrm{T}$ and C $(n=140)$ kidney samples. Expression of GUSB, RPL13, and
\end{abstract}

Electronic supplementary material The online version of this article (doi:10.1007/s13277-014-2566-9) contains supplementary material, which is available to authorized users.

P. M. Wierzbicki $(\square) \cdot$ A. Rybarczyk $\cdot$ T. Slebioda $\cdot$

M. Stanislawowski $\cdot$ A. Wronska $\cdot$ Z. Kmiec

Department of Histology, Faculty of Medicine, Medical University

of Gdansk, ul. Dębinki 1, PL 80-211 Gdańsk, Poland

e-mail: pwierzb@gumed.edu.pl

J. Klacz $\cdot$ M. Matuszewski

Department of Urology, Faculty of Medicine, Medical University of Gdansk, Gdańsk, Poland

A. Kowalczyk

Department of Human Histology and Embryology, Faculty of Medical Sciences, University of Warmia and Mazury, Olsztyn, Poland the $R P L 13+R P L P 0$ pair were independent of clinical/sample variables. Normalization of TP53 expression levels showed variability of GAPDH and ACTB assays. GUSB or RPL13 assays should be used in mccRCC for qPCR data normalization whereas GAPDH and ACTB assays should be avoided. Prior RG studies should precede each qPCR gene expression study since $R G$ selection is associated with the origin and proportion of specimens.

Keywords ccRCC $\cdot$ Metastasis $\cdot$ Reference gene $\cdot R P L 13$. GUSB $\cdot$ Quantitative PCR

\section{Introduction}

Renal cell carcinoma (RCC) is the third most common genitourinary malignancy, and its incidence has increased in the last 20 years [1]. The most frequent RCC subtype, clear-cell renal carcinoma (ccRCC) is characterized by a very high mortality rate of $40 \%$, due to distant metastases found in $30 \%$ of RCC-diagnosed patients [2]. Although numerous prognostic RCC markers have been proposed (e.g., Ki67, TP53, CAIX) [3], there is an urgent need to perform gene expression studies of tumor/metastatic RCC in order to find new biomarkers [4]. Molecular analyses involve reverse transcription (RT), followed by quantitative PCR (qPCR), and the final expression results of target genes are based on normalization to any stably expressed internal reference gene (RG), measured in the same sample [5]. Expression level of a properly selected RG cannot be influenced by any clinical variable of the analyzed specimens/patients, i.e., sample origin, disease stage, or a pharmacological treatment $[6,7]$.

Most ccRCC gene expression studies are normalized to $G A P D H$ or $A C T B$ genes [6], whose variable expression levels were noticed in other malignancies [8-10]. Therefore, the first aim of our study was to select the most stable RG among 15 
potential candidates in clinical material of primary nonmetastasic and metastasic tumor ccRCC matched with normal kidney tissue and ccRCC-origin metastasized tissues.

The second aim of the study was to analyze TP53 gene expression rate with the use of obtained normalization data of all RGs in order to show that the gene expression results in ccRCC strongly depended on RG selection. The results of such molecular approach have not been published yet.

\section{Material and methods}

Patients and samples

Tissue samples were collected from 70 patients with ccRCC undergoing radical nephrectomy at the Department of Urology of the Medical University of Gdansk (MUG), Poland, between January 2011 and May 2013. The use of tissue material was approved by the Medical Ethical Committee of the MUG (decision no. NKEBN/4/2011), and informed written consent regarding the use of tissue was obtained before surgery from each ccRCC patient. One hundred fifty-two samples were classified into four groups as shown in Fig. 1. Thirty-five ccRCC cases did not show metastases at the time of nephrectomy whereas local and distant metastases were diagnosed in $35 \mathrm{ccRCC}$ patients (metastasized ccRCC; mccRCC); five mccRCC cases showed distant metastasis: lung $(n=2)$, brain $(n=2)$, brain and liver (one patient) (Table 1). Other mccRCC patients possessed metastases located in regional paracaval or paraaortic lymph nodes. Metastases were also diagnosed in adrenal gland and vein thrombus. From all 70 patients, primary tumor (further named as " $\mathrm{T}$ ") and corresponding noncancerous fragments (named as "C") of the kidney were obtained. Additionally, from 12 mccRCC patients, apart from tumor and kidney tissue, we also collected metastasized tissue samples (named "M") from regional lymph nodes and adrenal glands $(n=10$ and $n=2$, respectively) due to additional lymphadenectomy and/or adrenectomy performed during nephrectomy (Fig. 1); metastasized tissue specimens from remaining 23 mccRCC cases were not obtained for this study. There was a positive correlation between TNM stage grouping and Fuhrman's nuclear grades, $r_{s}=0.52, P<0.001$, Spearman's test.

\section{Material acquisition}

The dissected tissue samples of primary ccRCC tumor, normal kidney, and adrenal gland (ca. $7 \pm 2 \mathrm{~mm} \times 7 \pm 2 \mathrm{~mm} \times 7 \pm 2 \mathrm{~mm}$ ) or the whole lymph node (ca. $10 \mathrm{~mm} \times 10 \mathrm{~mm} \times 10 \mathrm{~mm}$ ) were collected in the operating room no longer than $20 \mathrm{~min}$ after the kidney resection and placed in approximately five volumes of RNAlater (Ambion Inc., Austin, TX, USA). Three sectioned pieces of each sample were made. The central piece was used for RNA extraction, while the two side pieces were fixed in formalin and embedded in paraffin, followed by H\&E staining and the examination performed by pathologist.

\section{RNA extraction and DNA digestion}

Total RNA isolation was performed using GeneMATRIX Universal RNA Purification Kit (Eurx, Gdansk, Poland). Briefly, the tissues were homogenized in 2-ml tubes with ceramic beads (Blirt, Gdansk, Poland) in the presence of $300 \mu \mathrm{l}$ lysis buffer (Eurx) in the MagnaLyser apparatus (Roche Diagnostics Deutschland GmbH, Mannheim, Germany) for $45 \mathrm{~s}$ at $6,000 \mathrm{rpm}$. Further processing was performed following the manufacturer's (Eurx) protocol. Isolated RNA was eluted with $70 \mu \mathrm{l}$ of nuclease-free water (Eurx), followed by quantification with spectrophotometer (Nanodrop ND 1000, Thermo Fisher Scientific, Fitchburg, WI, USA). The RNA integrity and quality were characterized by RNA integrity number (RIN) with the RNA 6000 Nano Kit using the Eukaryote Total RNA Nano Chip and Bioanalyzer 2100 apparatus (Agilent Technologies, Santa Clara, CA, USA). Next, $20 \mu$ l of extracted RNA was treated with TURBO DNA-free kit (Ambion) according to manufacturer's protocol.

First-strand cDNA synthesis

Complementary DNAs (cDNAs) were polymerized from $2 \mu \mathrm{g}$ total RNA (100 ng RNA/1 $\mu$ l RT reaction) of each sample using $0.5 \mu \mathrm{g}$ oligo $(\mathrm{dT})_{18}$ primers (Sigma-Aldrich, Munich, Germany), 200 U RevertAid Reverse Transcriptase, $1 \mathrm{mM}$ dNTP mix, and 2 U Ribo-Lock (Fermentas-Thermo Fischer Scientific, Fitchburg, WI, USA). RT reaction was performed according to manufacturer's protocol, and the resulting cDNA was stored at $-25^{\circ} \mathrm{C}$ after $10 \times$ dilution with nuclease-free water to be used as the template in qPCR analysis.

\section{Design and validation of reference gene primers}

The primers were designed using Primer-BLAST software. The calibration curves for all gene-specific qPCR assays were performed (data not shown), and the resulting calibration curves' data are presented in Table 2.

The selection of RG assays for this study was based on the following: MeSH database search for the most commonly used RGs in ccRCC and in other cancers; previous literature results of normalization studies of kidney and other cancers [6, 10-14] and the commercially available RG sets (Roche Diagnostics, SA Biosciences, Life Technologies/Applied Biosystems).

For the RGs assays, the $15-\mu$ l reaction mixture included $1.5 \mu \mathrm{l} 10 \times$ diluted sample cDNA, $0.2 \mu \mathrm{M}$ each forward and reverse primers and SensiFast Sybr ${ }^{\mathrm{TM}}$ No-Rox kit (Bioline, London, UK). qPCR reactions for all RGs were performed in 


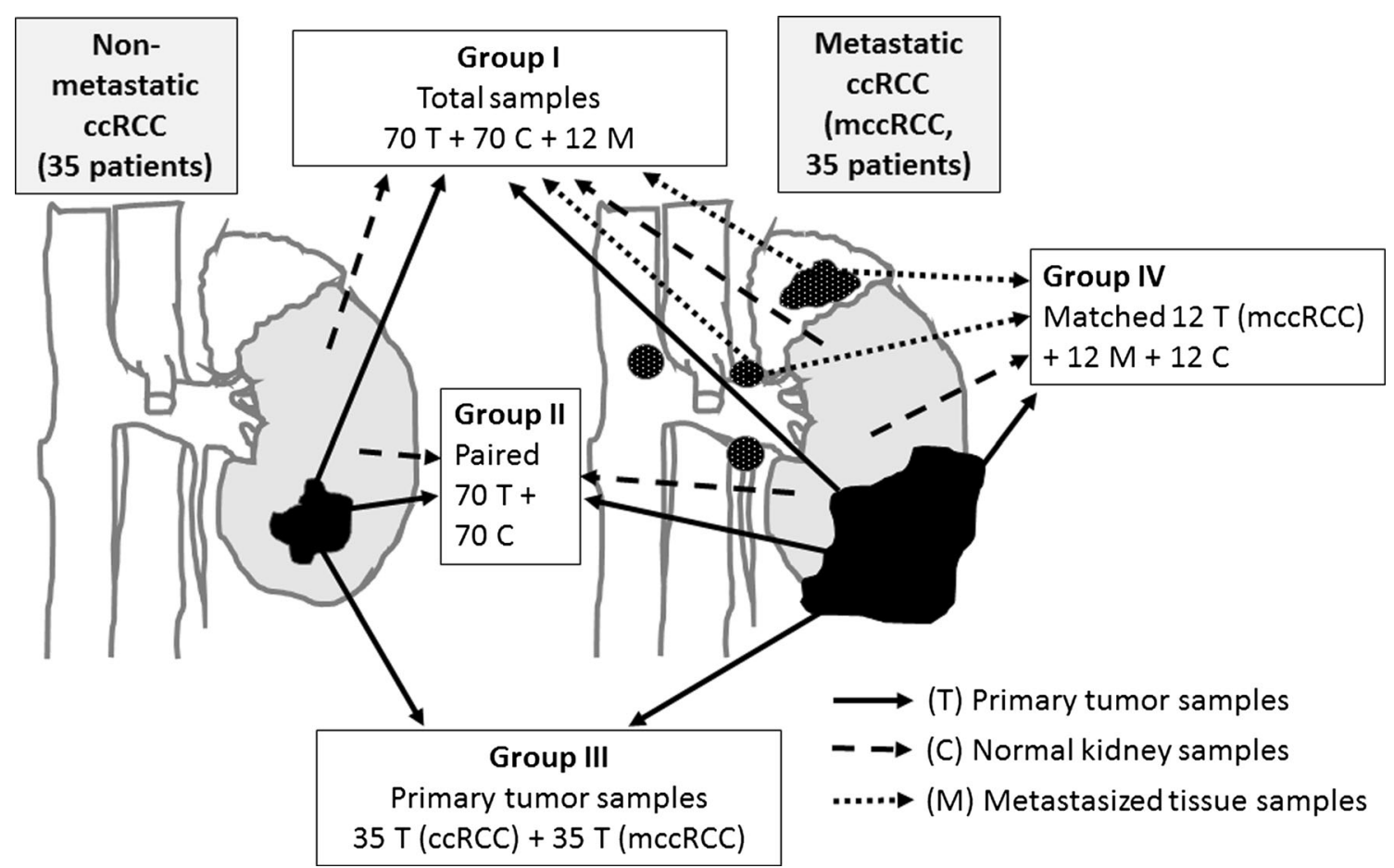

Fig. 1 Sample origin and division into groups. Seventy patients undergoing radical nephrectomy were characterized by the local or distant metastases diagnosed in 35 cases (metastatic, mccRCC group) and 35 were nonmetastatic at the time of surgery. Shaded color represents normal kidney, black pattern represents primary tumor, and white-dotted black pattern shows regional metastasis to adrenal gland, paraaortic, and

triplicate in StepOne Plus apparatus (Life Technologies/ Applied Biosystems, Grand Island, NY, USA), and the geometric mean of cycle threshold $(\mathrm{Ct})$ values was used in further analyses with StepOne Software ver. 2.2 (Life Technologies/ Applied Biosystems). We set runs for each gene assay separately. Each $\mathrm{qPCR}$ run contained paired $\mathrm{T} / \mathrm{C}$ or $\mathrm{T} / \mathrm{C} / \mathrm{M}$ paracaval lymph nodes. Primary mccRCC tumors were characterized by the cancer spreading beyond Gerota's fascia or into large veins (not shown to make figure lucid). From 12 mccRCC patients, the metastasized tissues were collected (arrows point example tissues), and together with matched primary tumor and normal kidney samples, group IV was created

samples, no-template control (water instead of cDNA), and $10 \times$ diluted pooled cDNA as a run-to-run precision control.

Intra-run and inter-run precision control tests were set using $10 \times$ diluted pooled cDNA in the same conditions as routine RGs assays. The intra-batch control was based on qPCR reactions for GUSB assay in 15 replicates during the same

Table 1 Demographic and pathologic classification of ccRCC patients

\begin{tabular}{|c|c|c|c|c|c|c|}
\hline \multicolumn{2}{|l|}{ Patients/specimens } & $\begin{array}{l}\text { Variable } \\
\text { Group division }\end{array}$ & $\begin{array}{l}\text { Total samples, } \\
n=70(\%)\end{array}$ & $\begin{array}{l}\text { Nonmetastatic ccRCC, } \\
n=35(\%)\end{array}$ & $\begin{array}{l}\text { Metastatic ccRCC, } \\
n=35(\%)\end{array}$ & $\begin{array}{l}\text { mccRCC cases with } \\
\text { metastasized samples, } \\
n=12(\%)\end{array}$ \\
\hline \multicolumn{3}{|l|}{ Age (years) ${ }^{\mathrm{a}}$} & $60.97 \pm 12.05$ & $60.57 \pm 13.41$ & $61.37 \pm 10.68$ & $61.42 \pm 6.86$ \\
\hline \multicolumn{3}{|l|}{$\operatorname{Sex}(\mathrm{M} / \mathrm{F})$} & $41 / 29$ & $20 / 18$ & $21 / 11$ & $8 / 4$ \\
\hline \multicolumn{2}{|l|}{ Tumor location } & Left/right kidney & $34 / 36$ & $23 / 12$ & $11 / 24$ & $5 / 7$ \\
\hline \multirow{4}{*}{\multicolumn{2}{|c|}{ Fuhrman's histological grade }} & 1 & $4(6)$ & $4(11.4)$ & - & - \\
\hline & & 2 & $35(50)$ & $25(71.2)$ & $10(28.5)$ & $2(17)$ \\
\hline & & 3 & $19(27)$ & $4(11.4)$ & $15(43)$ & $8(66.6)$ \\
\hline & & 4 & $12(17)$ & $2(6)$ & $10(28.5)$ & $2(17)$ \\
\hline \multirow[t]{4}{*}{ TNM stage grouping } & Nonmetastatic & T1-2N0M0 & $30(43)$ & $30(86)$ & - & - \\
\hline & & T2N0M0 & $5(7)$ & $5(14)$ & - & - \\
\hline & Metastatic & T1-2N1M0 T3N0-1M0 & $30(43)$ & - & $30(86)$ & $10(83)$ \\
\hline & & $\begin{array}{l}\text { T4N0-2M0T1-4N2M0 } \\
\text { T1-4N0-2M1 }\end{array}$ & $5(7)$ & - & $5(14)$ & $2(17)$ \\
\hline
\end{tabular}

${ }^{\mathrm{a}}$ Data shown as mean $\pm \mathrm{SD}$ 


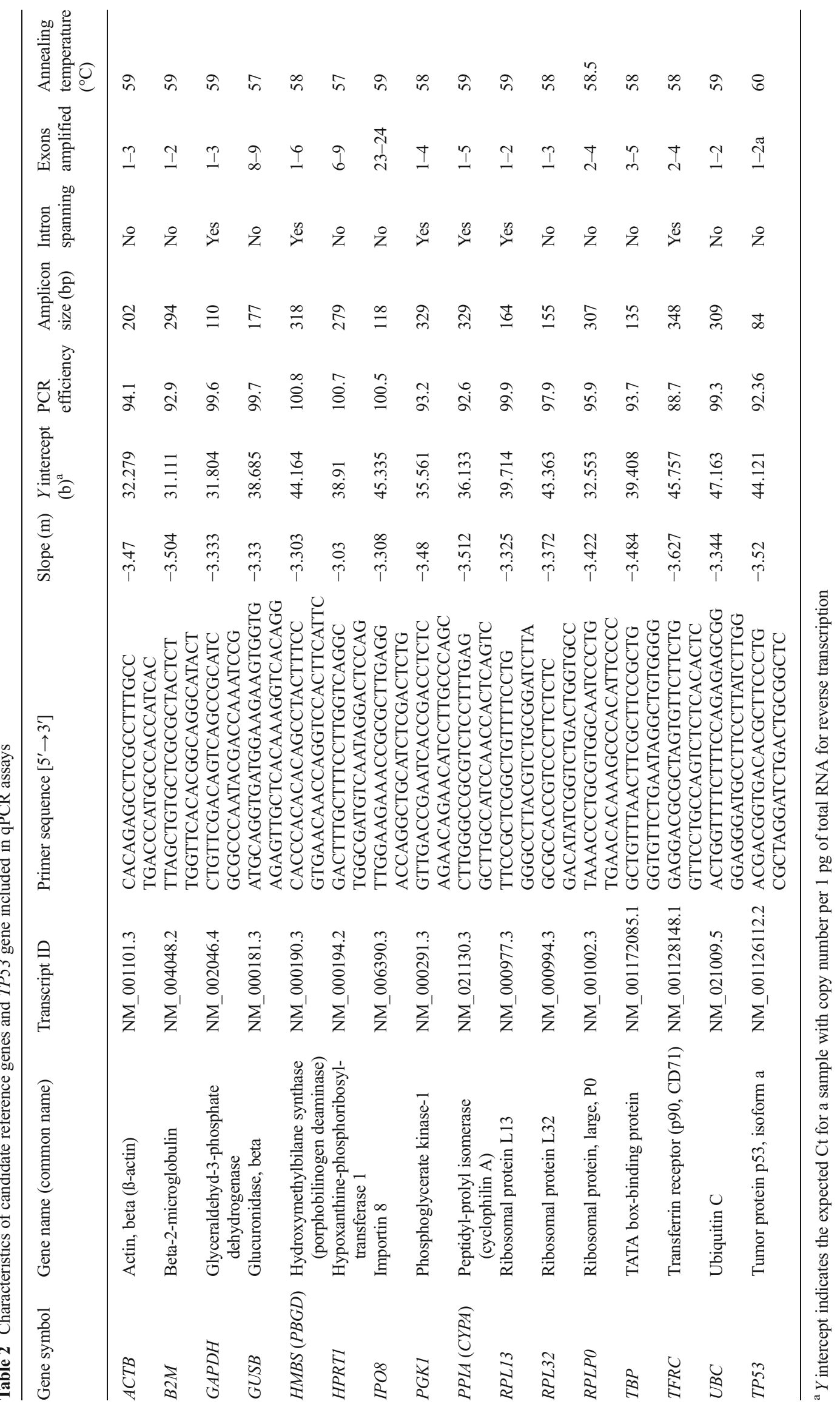


run. Inter-batch (run-to-run) test was based on data obtained from separate runs $(n=5)$ as described above, for each $\mathrm{RG}$ assay separately. In both tests, raw $\mathrm{Ct}$ data were collected and mean \pm standard deviation (SD) values were computed. $\mathrm{Ct}$ coefficient of variation ( $\mathrm{CtCV} \%$ ) values were calculated using the following formula: $\mathrm{CtCV}=\mathrm{SD} /$ mean $\times 100 \%$.

The gene TP53 which was targeted for normalization in ccRCC was amplified using the same conditions as RGs (details in Table 2).

Immunohistochemistry (IHC) methodology for TP53 protein is presented in supplementary materials.

\section{Data analysis}

Statistical analysis

Raw Ct data was transferred and calculated using GraphPad Prism, ver. 6.05 (GraphPad Software, San Diego, CA, USA). Normality of qPCR and clinical data was checked using D' Agostino and Pearson omnibus test. Nonparametric MannWhitney $U$ (A) and Kruskal-Wallis ANOVA tests (B) were used to compare clinical and qPCR data.

\section{Selection of single reference gene with the use of specialized tools}

The free online software tool, RefFinder [15] was applied, which uses the following algorithms: BestKeeper [16], NormFinder [17], GeNorm [7], and the relative delta $\mathrm{Ct}$ (dCt) [18] method. The final ranking from 1 (best RG) to 15 (least suitable RG) was shown as a result.

\section{Selection of $R G$ pair}

GeNorm data for a pair of $\mathrm{RG}$ was transferred from RefFinder results. For NormFinder RG pair selection, raw $\mathrm{Ct}$ data were calculated into arbitrary units (AU) with the use of calibration curves data (Table 2).

\section{Association of $R G$ expression and clinical data}

Raw Ct qPCR data of RG assays were compared with different clinical variables (Table 1) with the use of statistical tests described above (A or B).

\section{$R G$ s expression level versus sample origin}

Raw $\mathrm{Ct}$ data for each RG assay were divided according to the sample origin (T, C, or M) and analyzed group (I-IV); statistical association between samples' $\mathrm{Ct}$ values were assessed using A or B tests.

\section{Gene normalization based on $R G$ data}

The expression of TP53 was calculated using raw $\mathrm{Ct}$ data normalized with the use of $\mathrm{Ct}$ data of each RG. Further, expression data of TP53 in control samples was set to 1 and the expression of TP53 in T and M samples were calibrated to results obtained in control samples.

\section{Results}

RNA quality control

The average RNA concentration was $379.51 \pm 222.21 \mathrm{ng} / \mu \mathrm{l}$ (range 76.00-1,980.60 ng/ $\mu \mathrm{l}$ ). All samples presented high RNA quality and integrity; mean $\mathrm{A}_{260 / 280}$ ratio was $2.02 \pm$ 0.07 (range 1.96-2.13); average RIN values from all samples were $8.32 \pm 1.12$ (range 5.5-9.8).

Intra- and inter-batch qPCR precision control

As a part of a validation procedure of the presented $\mathrm{qPCR}$ method [19-21], pooled cDNA (10× diluted) from all samples was used as precision control material for each RG assay run. For intra-batch precision test mean $\mathrm{Ct} \pm \mathrm{SD}$ was $25.12 \pm 0.247$; therefore, $\mathrm{CtCV} \%$ value was $0.98 \%$ for $G U S B$ assay (Supplementary Fig. 1). The inter-batch precision values of $\mathrm{CtCV} \%$ ranged from $0.37 \%$ for GUSB to $0.74 \%$ for $H M B S$ (details not shown). Obtained results fulfill the precision criteria of bioanalytical method validation $(\mathrm{CtCV} \%<15 \%)$ $[19,22]$.

\section{Selection of a single RG}

Raw Ct data of all RGs assays (Supplementary Fig. 2) were analyzed by RefFinder [15]. The results for analyzed groups of samples (Fig. 1) are shown in Fig. 2. Since RefFinder utilizes summary results obtained from dCt, BestKeeper, GeNorm, and NormFinder, a brief presentation of each tool with results are described below.

\section{Relative delta $C t$}

$\mathrm{dCt}$ method was applied by Silver et al. [18] and is based on the mean $\mathrm{SD}$ value calculated between $\mathrm{Ct}$ data of each tested $\mathrm{RG}$ in comparison to other assays (e.g., GUSB vs $A C T B$, followed by GUSB vs GAPDH); RG assay with the smallest SD number is judged as the most stable. GUSB was the most stable RG in group I (all samples), GAPDH in group II (paired $70 \mathrm{~T}+70 \mathrm{C}$ ), followed by RPL13 in groups III (35 nonmetastatic vs 35 mccRCC) and IV (matched tumormetastasized control group of samples). 

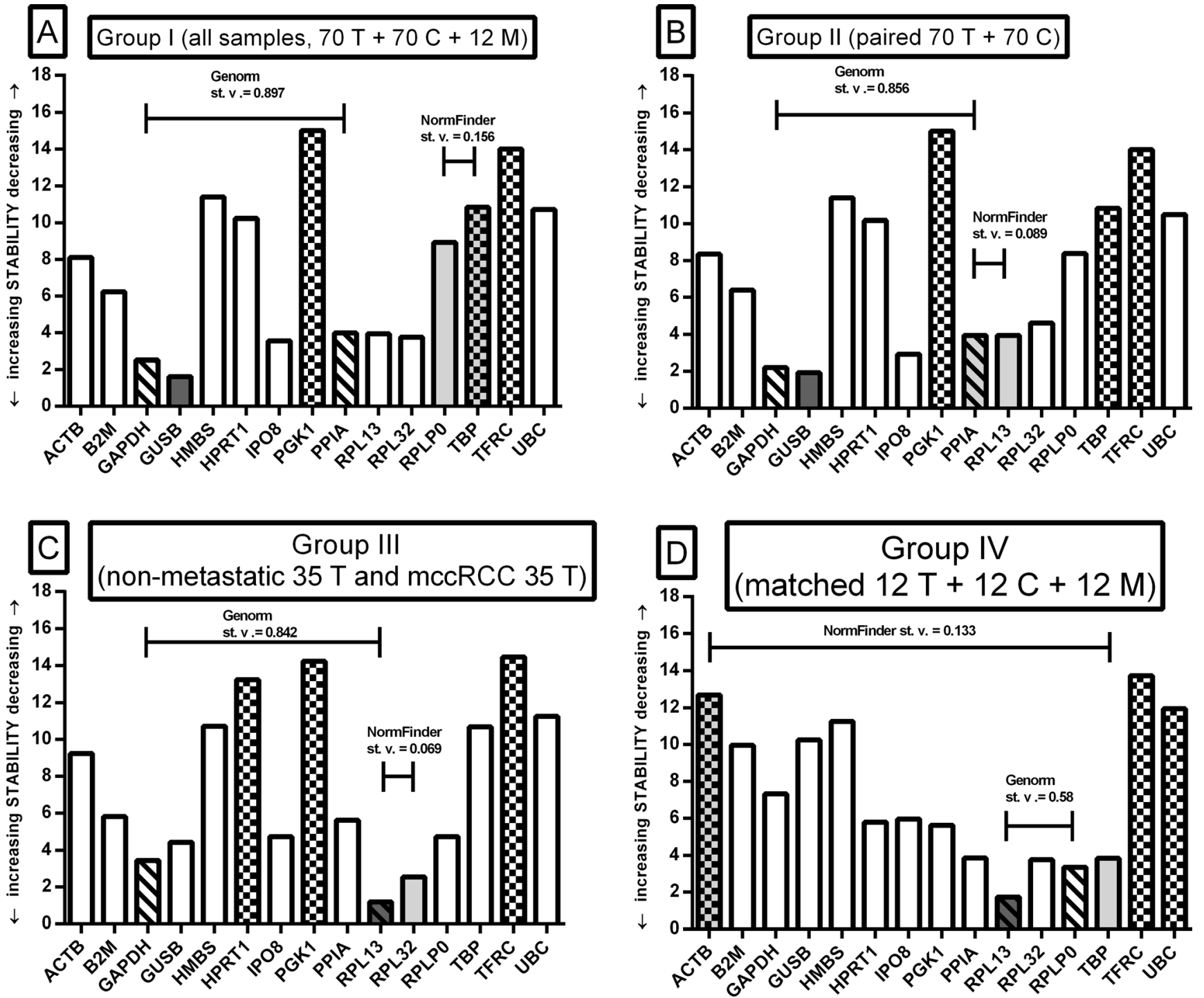

Fig. 2 Summary selection of best single RG or RG pair with the use of RefFinder, GeNorm, and NormFinder. a All samples $(n=152)$, b paired primary tumor and control kidney samples $(n=140)$, c primary nonmetastatic and mccRCC tumor samples $(n=70)$, $\mathbf{d}$ metastatic group with matched tumor, normal, and metastatic samples $(n=36)$. Dark gray

\section{BestKeeper}

The tool utilizes statistical calculations of each RG assay separately; RG with both smallest SD and Pearson's correlation coefficient values is considered as the most stable [16]. BestKeeper ranked GUSB as the most stable in groups I and II, whereas RPL13 and RPL32 were selected as best RGs in groups III and IV, respectively (Supplementary Table 1).

\section{NormFinder}

NormFinder utilizes a special algorithm which combines group division, absolute copy number of gene, and variation caused by biological and experimental factors [17]. Therefore,

bar shows the best single RG whereas chequered pattern shows the least stable genes in the analysis. Light gray bars depict RG pair selected by NormFinder (with stability value of the pair), while left diagonal bars represent GeNorm RG pair (with stability value of the pair)

raw $\mathrm{Ct}$ data had to be computed into $\mathrm{AU}$ by our team (see "Materials and methods" section) before NormFinder analysis. This algorithm selected GUSB as the best single RG in groups I and II and RPL32 and RPL13 in groups III and IV, respectively. NormFinder's RGs pair selection are presented further.

\section{GeNorm}

GeNorm calculates a normalization factor $(M)$ based on a geometric mean of $\mathrm{Ct}$ values of at least two RGs. Stepwise exclusion of the least stable gene allowed the genes to be ranked according to the stability value (the lower the $\mathrm{M}$ value, the higher the gene's expression stability) [7]. RefFinder's 
built-in GeNorm algorithm chose a combination of two candidate RGs with the lowest $M$ values, and the results are shown in Fig. 2.

\section{RefFinder summary ranking of a single $R G$}

RefFinder, free online tool, combines results of the mentioned single-RG algorithms. Besides RefFinder's availability and simplicity (copy-paste of raw Ct data staged in columns), the more RGs are tested, the more precise result is obtained. Figure 2 and Supplementary Table 1 show RefFinder ranking; GUSB was selected as the best RG in groups I and II, and RPL13 was the most suitable gene in groups III and IV.

\section{Selection of RG pair}

Due to recommendation to use at least two normalizers for gene expression analysis instead of one [5, 20], GeNorm and NormFinder results were applied. Due to differences in algorithms, no common scores between tools for any analyzed group of tissues (linked RGs in Fig. 2) was observed (with one exception; GAPDH + PPIA was selected by GeNorm as best pair in groups I and II). As a result we selected seven different $\mathrm{RG}$ pairs in four sample groups. In order to clarify this disagreement, we found that the $\mathrm{CtCV} \%$ factor has been recommended to validate NormFinder and GeNorm results [23]. We checked $\mathrm{CtCV} \%$ values for all selected $\mathrm{RG}$ pairs together with single RGs in different groups (Supplementary Table 2) and observed that NormFinder's selections were characterized by lower CtCV\% values than GeNorm's choices. Although such result shows that RGs pairs selected by NormFinder are more stable than GeNorm's pairs, we also found that for groups I-II, the best single RG showed lower CtCV\% value than for any RG pairs (6.58 and $6.19 \%$ for GUSB vs 8.21 and $8.36 \%$ for NormFinder's pair for groups I and II, respectively, Supplementary Table 2). Moreover, single $\mathrm{RG}$ for groups III and IV-RPL13 presents $\mathrm{CtCV} \%$ value between pairs of NormFinder and GeNorm. Based on those results, we suppose that despite $\mathrm{RG}$ pairs selected by NormFinder better meet the statistical requirement than GeNorm's, they do not outdistance single RG selection.

Relationship of RGs expression and experimental variables

Apart from selection of the most stable gene in selected groups with the use of specialized tools, the final result of RG selection has to be supported by manual statistics which utilize clinical variables and material division into subgroups according to their origin $[6,10,14]$. Only genes which are completely independent of those variables (in statistical perspective; $P>0.05$ between subgroups) can be finally chosen as a suitable $\mathrm{RG}$ in selected group of samples.
Association between RGs level and clinical status of ccRCC patients

Single RGs qPCR data of all 152 samples (Supplementary Fig. 2) were compared to clinical data of the ccRCC patients (Table 1). We also added comparison of RG pairs selected by GeNorm or NormFinder algorithms; the statistical results are shown in Table 3. The expression of any genes or RG pairs was not associated with gender and age of patients. Interestingly, we observed that GAPDH, GUSB, IPO8, RPL13, RPL32, and UBC genes, as well as RPLPO+TBP, $R P L 13+R P L 32, R P L 13+R P L P 0$, and $A C T B+T B P$ RG pairs, were the only assays whose expression did not depend $(P>0.05)$ on cancer progression. Since the expression levels of remaining RGs were associated with at least one selected clinical factor, they should not be further included in normalization panel of ccRCC studies (Table 3).

\section{Analysis of $R G$ expression in subset of biopsies}

Expression data of each single RG in 152 samples were divided into groups I-IV, followed by statistical comparison according to their origin; e.g., expression levels of $70 \mathrm{~T}$ versus $70 \mathrm{C}$ for group II. Summary plots are presented in Fig. 3. We observed that the higher the sample heterogeneity occurs in analyzed group, the fewer the genes share similar (originindependent; $P>0.05$ ) expression pattern between subgroups; if $70 \mathrm{~T}$ versus $70 \mathrm{C}$ (group II) were assessed, expression pattern of six genes was comparable (Fig. 3b, $P>0.05$ ) in comparison to group I with only four genes when $12 \mathrm{M}$ subgroup was introduced. We therefore observed the highest similarity between RG expression levels between samples when nonmetastatic versus metastatic tumor specimens were compared (group III, Fig. 3c). As a result, candidate genes which passed this statistical test can be considered in final $\mathrm{RG}$ result in selected groups of samples.

Comparable statistical analyses were performed for seven RG pairs selected by GeNorm and NormFinder (Fig. 4). We observed that only $G A P D H+R P L 13$ and $R P L 13+R P L P 0$ pairs share similar expression levels in groups III and IV, respectively; therefore, other RG pair should be omitted from the final selection.

Impact of reference gene on the relative expression of TP53 gene

The expression analysis of the target gene TP53 were used in this study to demonstrate the effect of different normalization genes on the relative expression data (Fig. 5a, b). For paired tumor and normal samples (group II), we observed increased expression of TP53 if $A C T B, B 2 M, G A P D H$, or RPLPO were 
Table 3 Statistical relationship between data of ccRCC patients and qPCR data of single reference genes and RG pairs

\begin{tabular}{|c|c|c|c|c|c|}
\hline Gene pair & Sex & Age & TNM stages & $\begin{array}{l}\text { Nonmetastatic vs metastatic } \\
\text { ccRCC (TNM stages grouped) }\end{array}$ & Fuhrman's histological grade (1-4) \\
\hline$A C T B$ & ns & ns & ns & ns & 0.04 \\
\hline$B 2 M$ & ns & ns & ns & ns & 0.0026 \\
\hline$G A P D H$ & ns & ns & ns & ns & ns \\
\hline GUSB & ns & ns & ns & ns & ns \\
\hline$H M B S$ & ns & ns & 0.0066 & 0.033 & ns \\
\hline HPRT1 & ns & ns & ns & ns & 0.002 \\
\hline IPO8 & ns & ns & ns & ns & ns \\
\hline$P G K 1$ & ns & ns & $<0.0001$ & 0.001 & 0.0075 \\
\hline PPIA & ns & ns & ns & ns & 0.003 \\
\hline$R P L 13$ & ns & ns & ns & ns & ns \\
\hline RPL32 & ns & ns & ns & ns & ns \\
\hline$R P L P O$ & ns & ns & 0.0046 & 0.002 & ns \\
\hline$T B P$ & ns & ns & 0.0001 & 0.0029 & 0.0003 \\
\hline TFRC & ns & ns & ns & ns & 0.0026 \\
\hline$U B C$ & ns & ns & ns & ns & ns \\
\hline$G A P D H+P P I A^{\mathrm{a}}$ & ns & $\mathrm{ns}$ & 0.0011 & 0.0011 & ns \\
\hline$R P L P 0+T B P^{\mathrm{b}}$ & ns & ns & ns & ns & ns \\
\hline$P P I A+R P L 13^{\mathrm{b}}$ & ns & ns & 0.0012 & 0.0005 & 0.02 \\
\hline$G A P D H+R P L 13^{\mathrm{a}}$ & ns & ns & 0.0245 & 0.011 & ns \\
\hline$R P L 13+R P L 32^{\mathrm{b}}$ & ns & ns & ns & ns & ns \\
\hline$R P L 13+R P L P 0^{\mathrm{a}}$ & ns & ns & ns & ns & ns \\
\hline$A C T B+T B P^{\mathrm{b}}$ & ns & ns & ns & ns & ns \\
\hline
\end{tabular}

Ct data was calculated as geometric mean of each assay. Statistical tests used: Mann-Whitney $U$ test - sex, nonmetastatic $(\mathrm{T} 1-2 \mathrm{~N} 0 \mathrm{M} 0+\mathrm{T} 2 \mathrm{~N} 0 \mathrm{M} 0)$ versus metastatic (T1-2N1M0, T3N0-1M0 + T4N0-2M0, T1-4N2M0, T1-4N0-2M1) ccRCC; Kruskal-Wallis ANOVA—age, TNM stage, Furhman's histological grade $(1-4) . P<0.05$. ns: $P>0.05$. Ct data were used for statistical comparisons

${ }^{\mathrm{a}} \mathrm{RG}$ pair as selected by GeNorm for groups I-IV

${ }^{\mathrm{b}} \mathrm{RG}$ pair as selected by NormFinder for groups I-IV

used for normalization. We also observed that for the least suitable RGs (chequered bars in Fig. 5a), there were no statistically significant differences between $\mathrm{T}$ and $\mathrm{C}$ samples.

When the matched $12 \mathrm{~T} / \mathrm{C} / \mathrm{M}$ samples were investigated (Fig. 5b), the expression pattern of TP53 was different than for the $70 \mathrm{~T} / \mathrm{C}$ group, i.e., we observed decreased TP53 expression in $\mathrm{T}$ samples for 11 of $15 \mathrm{RGs}$, including $A C T B$ and $G A P D H$, as well as when GeNorm and NormFinder RG pairs were used for normalization $(P<0.05$, Fig. $5 b)$.

Based on a well-documented decreased expression pattern of TP53 gene in ccRCC tumor samples [24, 25], we decided to apply candidate RGs which showed significant under expression of TP53 in tumor samples in both normalization approaches (group II and group IV). Therefore, only GUSB, $I P O 8, P P I A$, and RPL13 genes, as well as PPIA +RPL13, $R P L 13+R P L P 0$, and $A C T B+T B P$ pairs, passed this test. The different levels of TP53 expression for $A C T B, G A P D H$, and $B 2 M$ in relation to number of analyzed cases should exclude those genes from RG panel for ccRCC, since the expression results of TP53 cannot change by the increased number of analyzed samples (i.e., under expression of TP53 when $12 \mathrm{~T} /$ $\mathrm{C}$ were selected versus overexpression of TP53 when $70 \mathrm{~T} / \mathrm{C}$ was analyzed). We also observed only small increase of TP53 expression (ca. $2 \times$ increase vs control) in metastasized samples when GAPDH was utilized for normalization in contrast to $10 \times$ higher expression when RPL13 was used as $\mathrm{RG}$ (Fig. 5b).

Additionally, we checked the presence of TP53 protein in matched biopsies of T/M/C samples (group IV) with the use of immunohistochemistry (IHC, supplementary methods). IHC staining showed high expression of TP53 in normal kidney, with its dispersed distribution in the cytoplasm of epithelial cells. On the contrary, in tumor ccRCC slides, we observed a high accumulation of TP53 mainly in the nuclei of malignant cells (Fig. 6e-h). Moreover, we observed massive presence of TP53 protein in all metastasized and normal immune cells of lymph nodes (Fig. 6c, d), which was in accordance with upregulation of TP53 mRNA (Fig. 5b) in metastasized samples. 


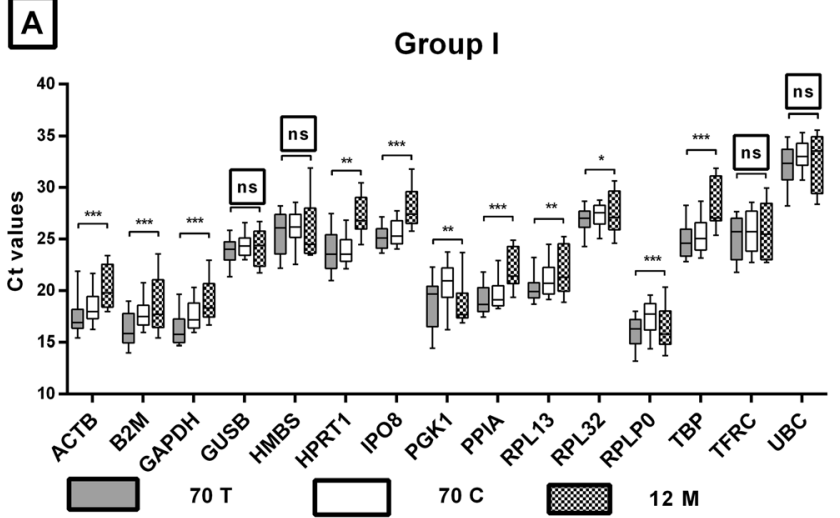

C

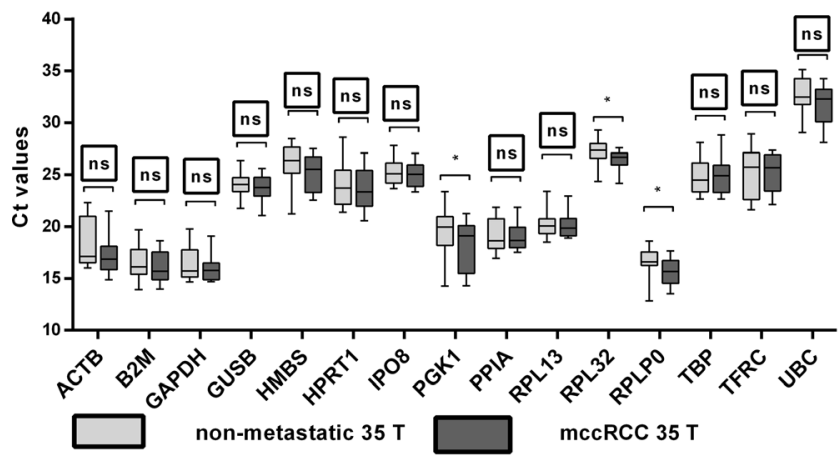

Fig. 3 Expression levels of candidate reference gene assays in analyzed groups divided by sample origin. Summary results of all RG assays $(x$ axis) and $\mathrm{Ct}$ data ( $y$ axis). Box (median $\mathrm{Ct}$ and lower and upper quartiles) and whisker (10-90 \% Ct values) plot for each samples' subgroup. a All samples $(n=152)$, b paired primary tumor and control kidney samples $(n=$

\section{Reference gene final selection}

Based on single reference gene selection (RefFinder) together with exclusion results of clinical/biological versus RG expression statistical tests, as well as TP53 normalization approach, we found that GUSB is the most suitable single RG for groups I and II and RPL13 is best RG for groups III and IV (Table 4). Different pattern occurs for RG pair selection, since only $R P L 13+R P L P 0$ selected by the GeNorm algorithm (Table 5) fulfils statistical criteria; therefore, for matched tumor-controlmetastasized ccRCC samples (group IV) RPL13+RPLP0 pair may be considered for normalization in gene expression studies.

\section{Discussion}

In this study, we presented methods and results of selection of suitable RGs in metastatic ccRCC, because currently, there is no data concerning this important issue. A reliable
B

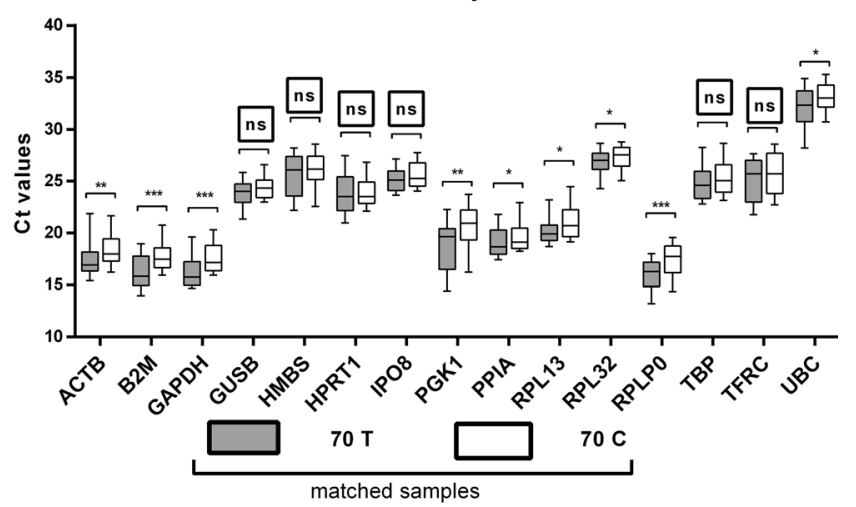

D

Group IV

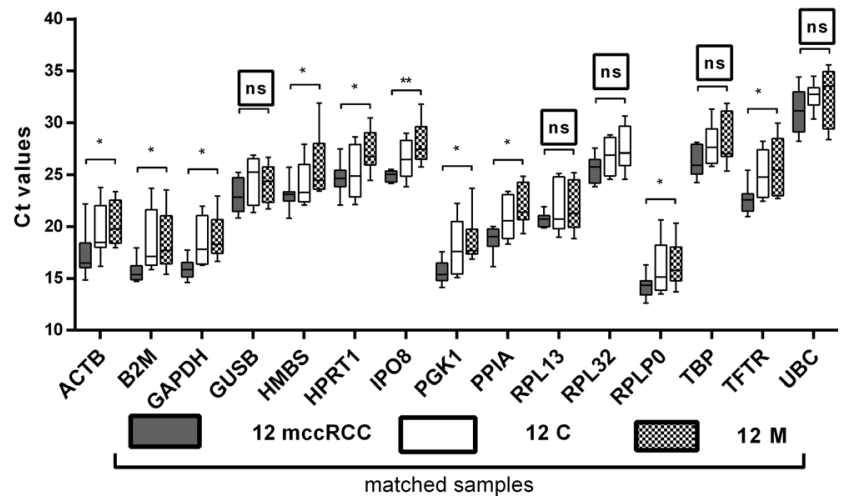

140), c primary nonmetastatic and mccRCC tumor samples $(n=70)$, d metastatic group with matched tumor, normal, and metastatic samples $(n=$ 36). Statistics used: a, d-Kruskal-Wallis ANOVA; b, c-Mann-Whitney $U$ test. $* 0.01<P<0.05 ; * * 0.001<P<0.01 ; * * * P<0.001 ; n s, P>0.05$ between subgroups

normalization project should be based on validation procedures related to analytical biochemistry $[6,19]$. Since the presented data contain standardization of sample preparation and RNA integrity assessment, followed by qPCR requirements $[5,20]$ - standard curve, precision tests (intra- and inter-run), and selectivity (melt curve) - we believe that our methodology and results can be utilized by other researchers.

To date, only three groups performed similar RG selection studies on tumor ccRCC compared to normal kidney tissue [6, $26,27]$, while Bjerregaard et al. focused on ccRCC versus renal oncocytoma [10]. When compared with the mentioned data, our study was based on nonmetastatic versus mccRCC cases and analyzed the highest number of RGs. Although RGs' suitability was calculated and ranked with the use of specialized tools, the limitation of those algorithms is the utilization of raw expression data without consideration for either clinical data or sample's primary localization. Therefore, the statistical comparison of clinical or specimen's origin versus expression data had to be evaluated with the use of manual statistics, since one of the basic requirement for RG 
Group I

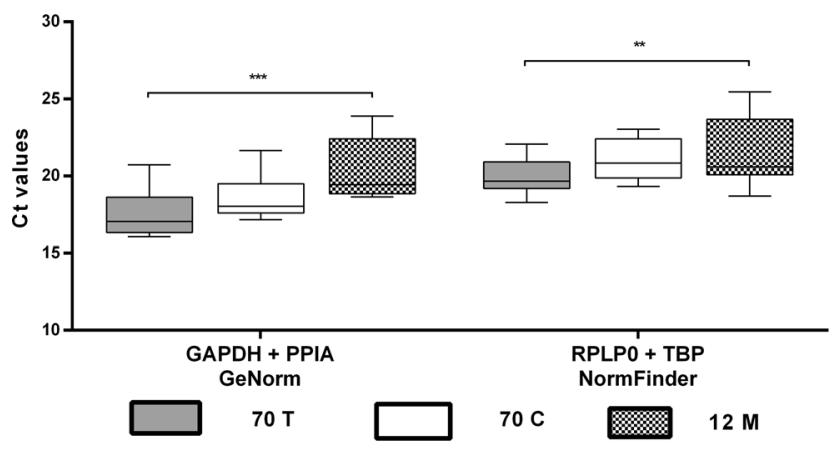

Group III

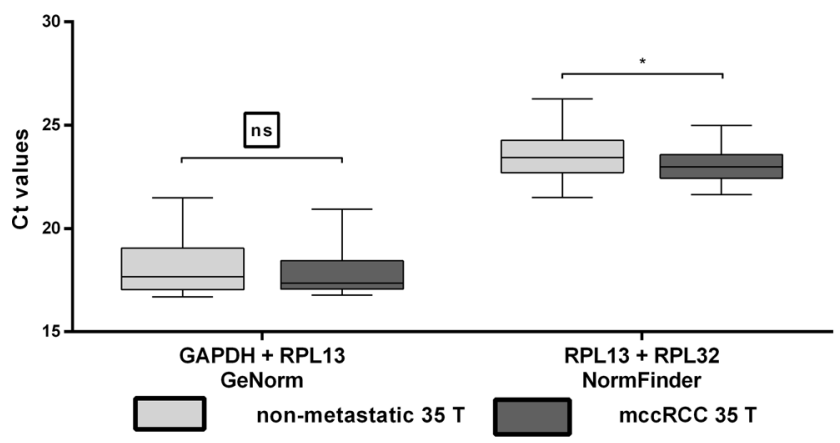

Fig. 4 Expression levels or candidate reference gene pairs in specimens' subgroups. RG pairs were selected by either GeNorm or NormFinder algorithms, separately for each analyzed group. Ct data were calculated

selection is the independence of expression from biological and clinical variables $[6,7]$. We therefore observed the independence of suitable RGs' expression from clinical factors, which was in accordance with other authors' observations [6, $27,28]$.

Our results of RG selection are not in agreement with other authors who focused on RCC. Although Jung et al. found $T B P+P P I A$ as the most suitable $\mathrm{RG}$ pair, their study on 25 cases introduced $24 / 1$ male/female (M/F) and no patients with diagnosed metastasis, whereas our project contained larger population sample $(41 / 29 \mathrm{M} / \mathrm{F})$ and 35 mccRCC (T3 or N12 or M1) cases. The most recent report on RG selection in ccRCC shows that PPIA and RPS13 (or their combination) is based on paired tumor control kidney specimens (no metastasized tissue) from $16(14 / 2 \mathrm{M} / \mathrm{F})$ ccRCC patients [27]. Furthermore, only 5 of 16 patients from the Dupasquier et al. study presented local or distant metastases [27]. Finally, in contrast to utilization of the same algorithms and manual statistics, ours and the mentioned studies data cannot be strictly compared, since they did not check stability of GUSB or RPL13 genes [6, 27].

The limitation of our study is, however, the lack of distant metastasized samples (bone, lung) and utilization of only 12 samples obtained from regional metastases. Therefore, our
Group II

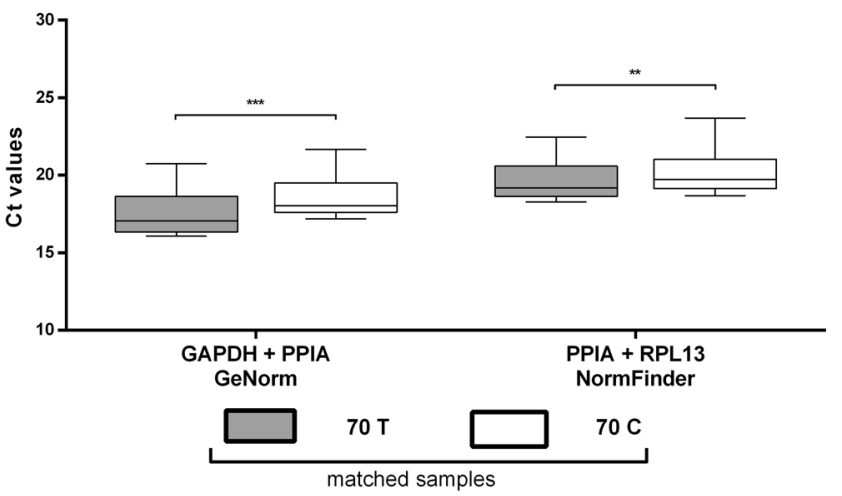

Group IV

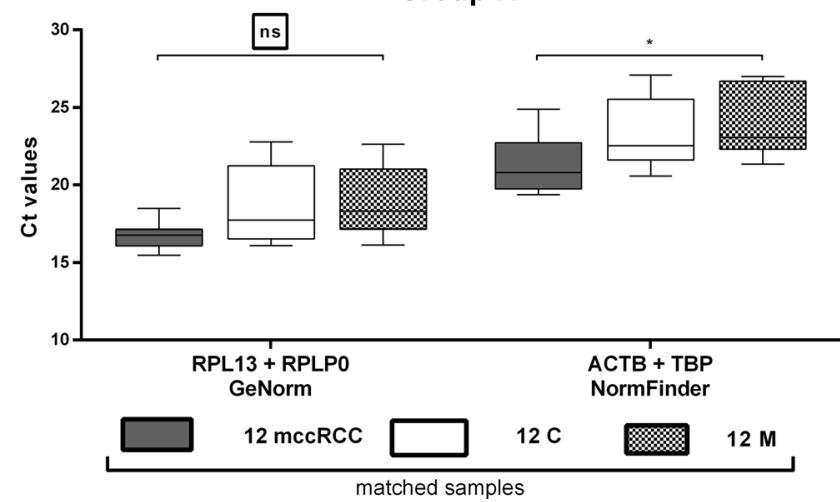

using geometric mean of $\mathrm{Ct}$ score for each gene. Figure legends according to Fig. 3

findings should be confirmed by independent studies performed by other teams.

Our results also contained the selection of RGs pair. Although the use of two or more RGs in gene expression studies has been strongly recommended by minimum information for publication of quantitative real-time PCR experiments (MIQE) guidelines [20], cancer gene expression studies rarely utilize more than one RG for the normalization [29-31]. In fact, the most recent review which focused on observance of MIQE in qPCR gene expression studies in colorectal cancer revealed that only 6 of $179(3.3 \%)$ analyzed studies (between 2006 and 2013) used two RGs [21]. Therefore, we do not suppose that the requirement for two or more RGs in gene expression studies is also followed in ccRCC; hence, we propose to use one but carefully selected RG. Additionally, despite the fact that GeNorm tool offers the evaluation of a number of RGs recommended for normalization (two or more RGs), we did not find any reference which uses three or more RGs in cancer gene expression studies. Finally, since no common results were found between individual algorithms or groups' divisions, followed by statistical failure of most selected RGs pairs, we propose to focus on single-RG normalization. 
Fig. 5 Normalization of TP53 gene expression with the use of RG data. In selected groups II and IV, the expression of TP53 for control samples (70 and $12 \mathrm{C}$ ) were set to 1 and expression values in the matched tumor (70 T) or tumor and metastasis (12

$\mathrm{T} / \mathrm{M}$ ) were calculated as multiplies. The columns represent the median and interquartile ranges of the TP53 gene expression. Dark gray bars represent the most stable single RG selected for the analyzed specimens' group; chequered pattern shows the least stable genes in the analysis, according to RefFinder results. Light gray bars show the relative expression normalized to geometric mean of RG pairs selected by GeNorm and NormFinder algorithms, respectively. a Relative expression in paired $70 \mathrm{~T}$ samples in relation to $70 \mathrm{C}$ specimens (expression set to 1). b Relative expression in matched $12 \mathrm{~T}$ (blank) and $12 \mathrm{M}$ (dotted boxes) in relation to $12 \mathrm{C}$ specimens. $* P<0.05$ between Tor $\mathrm{M}$ samples and control (Wilcoxon test), $\alpha P<0.05$ between matched $\mathrm{T}$ and $\mathrm{M}$ samples (Wilcoxon test). Please note that results for $70 \mathrm{~T}$ (a) and $12 \mathrm{M}$ (b) cannot be directly compared due to different control groups

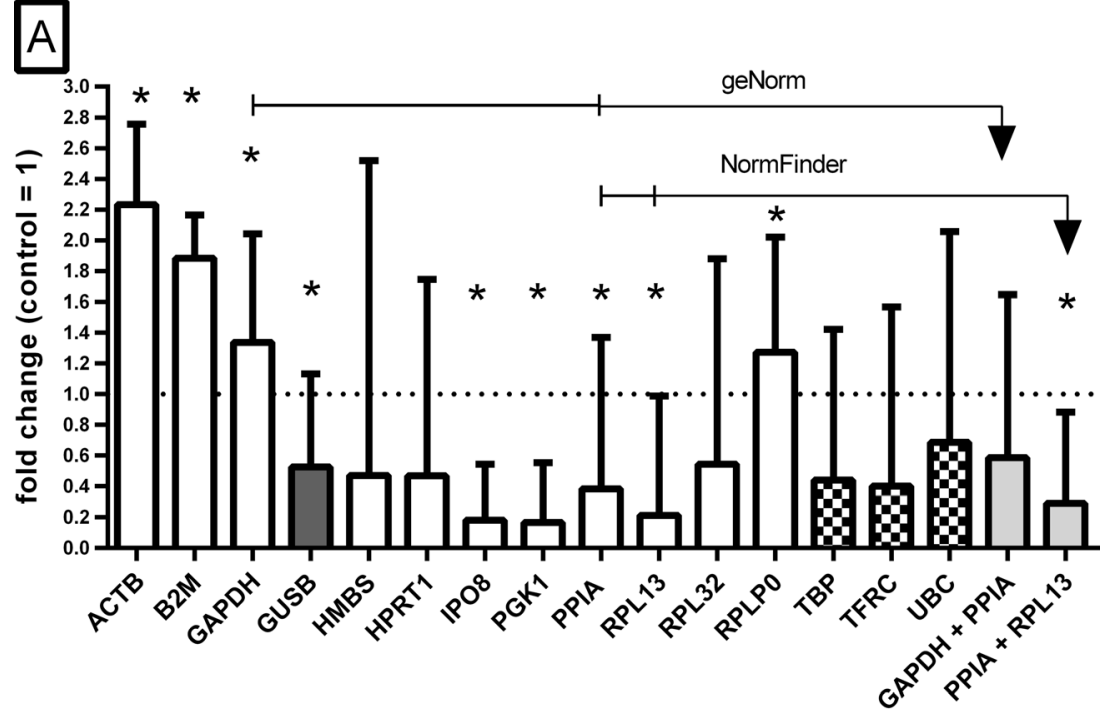

normalization approach for Group II (70 T/C)

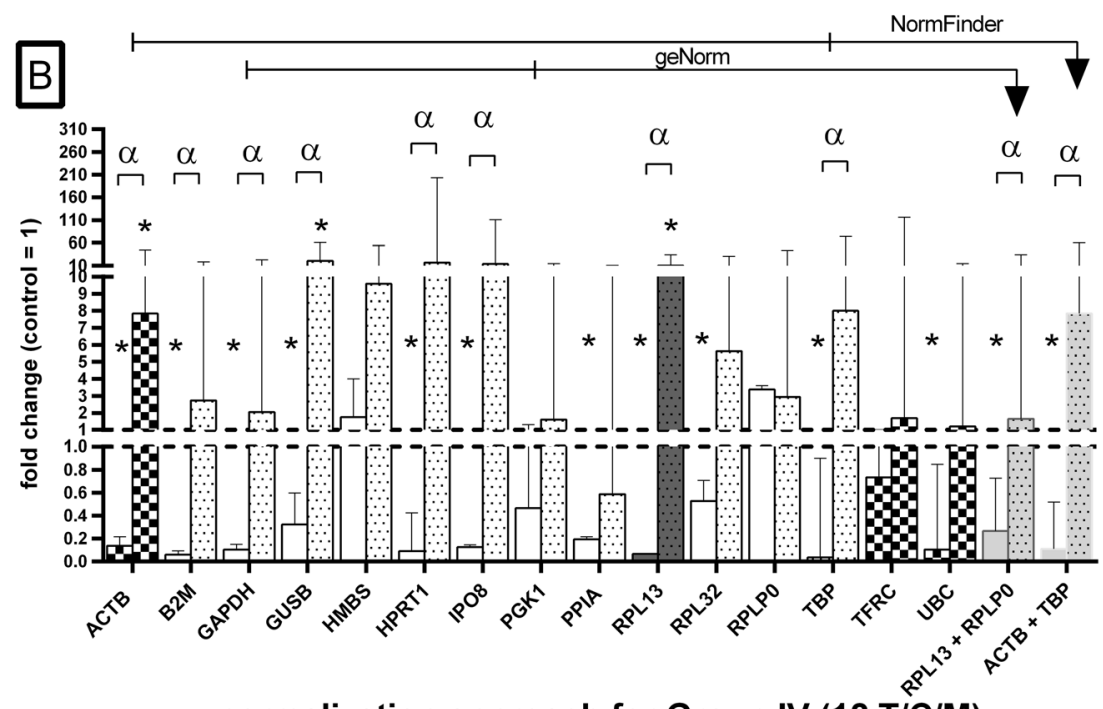

normalization approach for Group IV (12 T/C/M)
We chose to create different analyzed groups of samples and presented complex results based on this division. It was connected to the fact that we utilized a large number of specimens; therefore, we decided to present as much useful data as possible. Although the presentation of more than only one comparison (nonmetastatic vs metastatic tumor samples) [14] could be obscured, our results for more groups can be easily utilized by other teams working on different origin of samples, e.g., paired tumor control samples for studies of ccRCC cancer development markers.

Our normalization approach of TP53 gene expression has clearly shown that the choice of an appropriate reference gene can strongly affect final results of gene expression studies. We chose the TP53 tumor suppressor gene, whose decreased expression in tumor samples of ccRCC and other malignancies was proven by other studies [24, 25, 32, 33]. Apart from other presented statistical results in this study, we propose to exclude $G A P D H$ and $A C T B$ from the normalization panel, since false results can be obtained when normalized to those RGs. Although GAPDH is the most common RG in RCC studies and most author may disagree with our results, GAPDH expression stability should also be questioned when the biological characteristics of RCC is taken into consideration. Since tumor RCC is characterized by dysregulation of glucose metabolism [34], it is a strong support for nonconstant expression of GAPDH [23]. Moreover, it was noted that GAPDH protein level changes in RCC as well in other cancers [9]. Our results of TP53 normalization in metastasized group with the use of GAPDH versus RPL13 reinforced the variability of $G A P D H$, since we confirmed strong overexpression of 

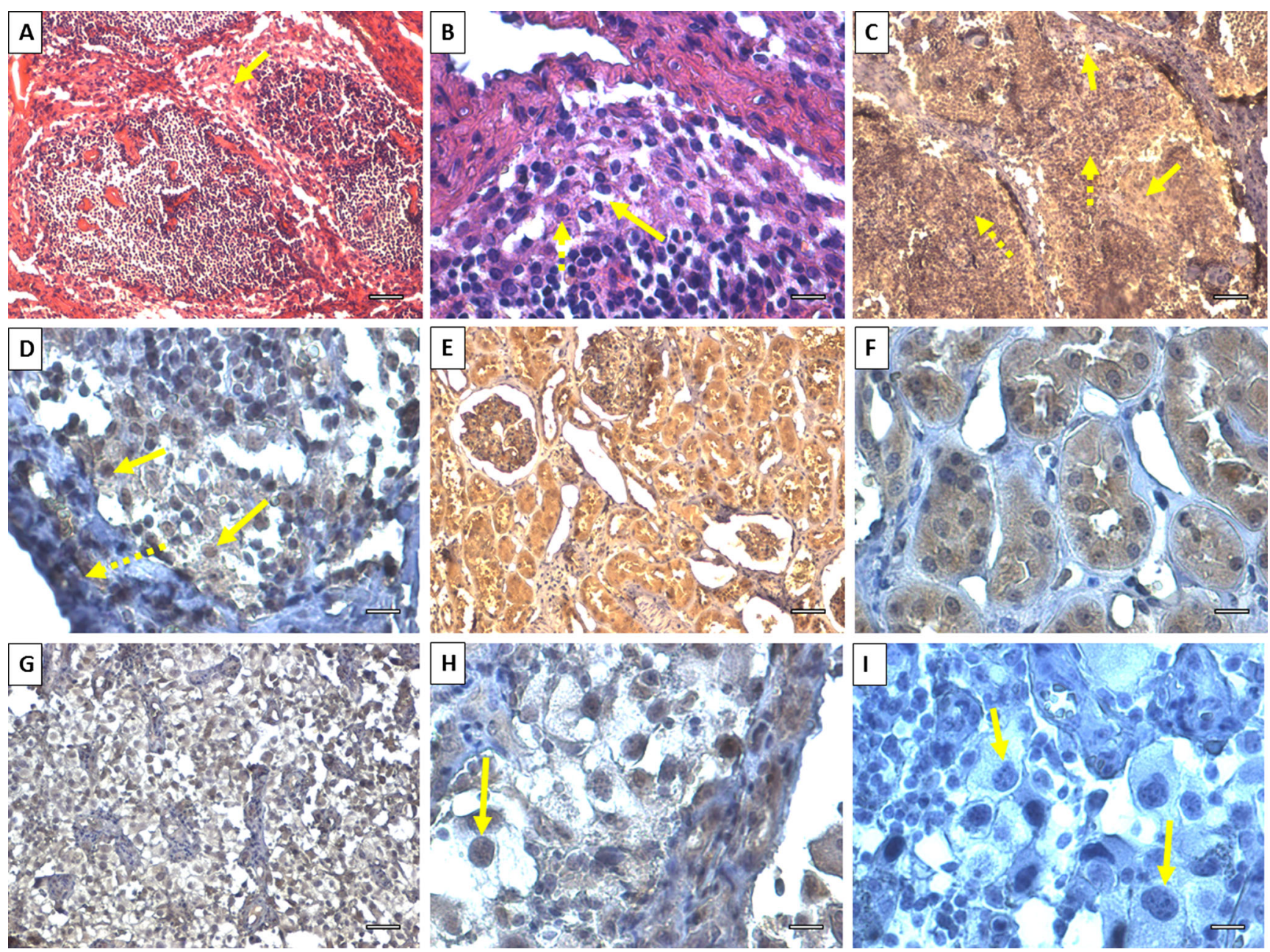

Fig. 6 Representative histological and immunohistochemical pictures of ccRCC patient's tissue (male, 73 years, Fuhrman grade 4, pT3aN1Mx). Hematoxylin and eosin staining of ccRCC metastasis to perirenal lymph node $\mathbf{a} \times 100, \mathbf{b} \times 400)$. Arrow shows metastasized cells with clear-cell and eosinophilic RCC pattern (dotted arrow). c, d IHC staining for TP53 protein presents high accumulation of protein in cytoplasm of immune cells (dotted arrow) and lower accumulation in cytoplasm of metastasized cells (solid arrows). d The presence of TP53 is limited mostly to nuclei of malignant cells; no TP53 presence in lymph node trabeculae (dotted arrow). e, f Normal kidney's cortex fragment stained for TP53; the very high presence of TP53 is found in the cytoplasm of podocytes and tubular cells. g, h IHC staining for TP53 in tumor ccRCC; the protein is limited mostly to nuclei of malignant cells. i Negative control (without primary $\mathrm{Ab}$, only hematoxylin staining) for TP53 in ccRCC $(\times 400)$; obviously big and irregular shape of nuclei with up to five visible nucleoli indicate Furhman's grade 4. Please note that high accumulation of TP53 in $\mathbf{h}$ obscures the nuclei details found in $\mathbf{i}$
TP53 in metastasized tissues (as calculated with the use of $R P L 13)$ by IHC, as well as other authors found its increase expression in this type of samples $[3,35]$. This point is another limitation of our study, since the RNA in situ hybridization (RNA ISH) should be applied in order to show the TP53 mRNA content in cells instead of protein and confirm the results obtained by qPCR method. Since this method is currently unavailable to our team (i.e., RNA ISH requires different sample preparation [36]), we aimed to confirm the general TP53 expression pattern in tumor-control-metastasized ccRCC samples by the means of IHC.

In comparison to GAPDH, GUSB and RPL13 proteins do not seem to be involved in ccRCC development, since GUSB is not engaged in intracellular metabolism, whereas RPL13 is highly expressed in the cytoplasm of all nucleated cells. Due to high stability, GUSB was noted as a suitable RG in lung [37] and ovarian [38] cancers, whereas RPL13 was the best RG in Alzheimer's disease [39] and in mesenchymal stem cell study [40]. We suppose that last reference is a key to the observed highest stability of RPL13 in groups III-IV and may be caused by the high proportion of poorly developed (highly aggressive, Fuhrman's stage 3-4) cells of tumor specimens in analyzed groups, which can be characterized by the increase deregulation or cellular machinery as compared to other specimens. Furthermore, the high differences in RG results between groups I-II and III-IV may be connected to the high proportion of metastatic tumor samples - from one fourth in group II to one half in group III, as well as to the 
Table 4 Final selection of a single RG in ccRCC groups based on summary data of normalization algorithm and manual statistics

\begin{tabular}{|c|c|c|c|c|c|c|c|}
\hline \multirow{2}{*}{$\begin{array}{l}\text { candidate } \\
\text { RGs }\end{array}$} & Group I & Group II & Group III & Group IV & \multirow{2}{*}{$\begin{array}{l}\text { qPCR vs } \\
\text { clinical } \\
\text { data }\end{array}$} & \multirow{3}{*}{$\begin{array}{l}\text { TP53 } \\
\text { normalization } \\
\text { assay }\end{array}$} & \multirow{3}{*}{$\begin{array}{l}\text { FINAL } \\
\text { single RG } \\
\text { selection }\end{array}$} \\
\hline & \multicolumn{4}{|c|}{ RefFinder ranking position for each group $\left\{\#^{\circ}\right\}$} & & & \\
\hline ACTB & & & Pass, $\left\{9^{\circ}\right\}$ & & & & \\
\hline$B 2 M$ & & & Pass, $\left\{8^{\circ}\right\}$ & & & & \\
\hline GAPDH & & & Pass, $\left\{3^{\circ}\right\}$ & & Pass & & \\
\hline GUSB & Pass, $\left\{1^{\circ}\right\}$ & Pass, $\left\{1^{\circ}\right\}$ & Pass, $\left\{4^{\circ}\right\}$ & $\begin{array}{l}\text { Pass, } \\
\left\{11^{\circ}\right\}\end{array}$ & Pass & Pass & $\begin{array}{l}\text { GUSB for } \\
\text { groups I } \\
\text { and II }\end{array}$ \\
\hline HMBS & $\begin{array}{l}\text { Pass, } \\
\left\{13^{\circ}\right\}\end{array}$ & $\begin{array}{l}\text { Pass, } \\
\left\{13^{\circ}\right\}\end{array}$ & Pass, $\left\{11^{\circ}\right\}$ & & & & \\
\hline HPRT1 & & $\begin{array}{l}\text { Pass, } \\
\left\{10^{\circ}\right\} \\
\end{array}$ & Pass, $\left\{13^{\circ}\right\}$ & & & & \\
\hline IPO8 & & Pass, $\left\{3^{\circ}\right\}$ & Pass, $\left\{5^{\circ}\right\}$ & & Pass & Pass & \\
\hline \multicolumn{8}{|l|}{ PGK1 } \\
\hline PPIA & & & Pass, $\left\{7^{\circ}\right\}$ & & & Pass & \\
\hline RPL13 & & & Pass, $\left\{1^{\circ}\right\}$ & Pass, $\left\{1^{\circ}\right\}$ & Pass & Pass & $\begin{array}{l}R P L 13 \text { for } \\
\text { groups III } \\
\text { and IV }\end{array}$ \\
\hline RPL32 & Pass, $\left\{4^{\circ}\right\}$ & & & Pass, $\left\{3^{\circ}\right\}$ & Pass & & \\
\hline \multicolumn{8}{|l|}{ RPLPO } \\
\hline$T B P$ & & $\begin{array}{l}\text { Pass, } \\
\left\{12^{\circ}\right\}\end{array}$ & Pass, $\left\{10^{\circ}\right\}$ & Pass, $\left\{4^{\circ}\right\}$ & & & \\
\hline TFRC & $\begin{array}{l}\text { Pass, } \\
\left\{14^{\circ}\right\}\end{array}$ & $\begin{array}{l}\text { Pass, } \\
\left\{14^{\circ}\right\}\end{array}$ & Pass, $\left\{15^{\circ}\right\}$ & & & & \\
\hline UBC & $\begin{array}{l}\text { Pass, } \\
\left\{11^{\circ}\right\}\end{array}$ & & Pass, $\left\{12^{\circ}\right\}$ & $\begin{array}{l}\text { Pass, } \\
\left\{13^{\circ}\right\}\end{array}$ & Pass & & \\
\hline
\end{tabular}

Pass - expression level of RG was nonsignificantly different between sample subgroups $(P>0.05)$ in group division; independent of some clinical factor $(P>0.05)$; or TP53 was statistically decreased $(P<0.05)$ in tumor samples when normalized to selected RG. Empty cells - RGs which did not fulfill the mentioned statistical criteria. Pale gray cells - the most suitable and common scores for specific RG

introduction of metastatic tissue samples in group IV. We wanted to emphasize this factor, because not only the different type but also the proportion between the numbers of samples of different origin have strong influence on RG selection.

Table 5 Final selection of RG pairs based on NormFinder or GeNorm results followed by manual statistics

\begin{tabular}{|c|c|c|c|c|c|c|c|}
\hline $\begin{array}{l}\text { candidate RGs } \\
\text { pair }\end{array}$ & Group I & Group II & Group III & Group IV & $\begin{array}{l}\text { qPCR vs } \\
\text { clinical } \\
\text { data }\end{array}$ & $\begin{array}{l}\text { TP53 } \\
\text { normalization } \\
\text { assay (group II } \\
\text { or IV) }\end{array}$ & $\begin{array}{l}\text { FINAL RG } \\
\text { pair } \\
\text { selection }\end{array}$ \\
\hline \multicolumn{8}{|l|}{$\begin{array}{l}\text { GAPDH + } \\
\text { PPIA }^{a}\end{array}$} \\
\hline $\begin{array}{l}\text { RPLPO + } \\
\text {TBP }^{b}\end{array}$ & & & & & Pass & Pass & \\
\hline \multicolumn{8}{|l|}{$\begin{array}{l}\text { PPIA + } \\
\text { RPL13 }^{b}\end{array}$} \\
\hline $\begin{array}{l}\text { GAPDH + } \\
\text { RPL13 }\end{array}$ & & & Pas: & & & & \\
\hline $\begin{array}{l}\text { RPL13 + } \\
R^{R} L 32^{b}\end{array}$ & & & & & Pass & & \\
\hline $\begin{array}{l}R P L 13+ \\
R P L P 0^{a}\end{array}$ & & & & Pass & Pass & Pass & $\begin{array}{l}\text { RPL13 + } \\
\text { RPLPO for } \\
\text { group IV }\end{array}$ \\
\hline $\begin{array}{l}\text { ACTB + } \\
T_{B P^{b}}\end{array}$ & & & & & Pass & Pass & \\
\hline
\end{tabular}

Pass - expression level of RGs pair was nonsignificantly different between sample subgroups $(P>0.05)$ in group division; independent of some clinical factor $(P>0.05)$; or TP53 was statistically decreased $(P<0.05)$ in tumor samples when normalized to selected RGs pair. Empty cells — RGs which did not fulfill the mentioned statistical criteria. X - test was not assessed for a selected pair. Pale gray cells — the most suitable and common scores for specific RGs pair

${ }^{\mathrm{a}}$ GeNorm RG pair selections for different groups

${ }^{\mathrm{b}}$ NormFinder RG pair selections for different groups 


\section{Conclusions}

For gene expression studies of mccRCC, we recommend to use a single RG (GUSB or RPL13) and to avoid the following RGs for normalization: $A C T B, B 2 M, G A P D H, T F R C$, and $U B C$.

Acknowledgment This study was supported by the grants N402 452839 and IP2010 045970 of the Polish Ministry for Science and Higher Education. We also thank M. Kogut, PhD, for general support, D. Wojcik, MSc., J. Kwiatkowska, MSc., and A. Markowska, $\mathrm{PhD}$, for laboratory support.

Conflicts of interest The authors declare that they have no conflict of interest.

Open Access This article is distributed under the terms of the Creative Commons Attribution License which permits any use, distribution, and reproduction in any medium, provided the original author(s) and the source are credited.

\section{References}

1. Dall'Oglio MF, Arap MA, Antunes AA, Cury J, Leite KR, Srougi M. Impact of clinicopathological parameters in patients treated for renal cell carcinoma. J Urol. 2007;177(5):1687-91.

2. Novara G, Martignoni G, Artibani W, Ficarra V. Grading systems in renal cell carcinoma. J Urol. 2007;177(2):430-6.

3. Laird A, O'Mahony FC, Nanda J, Riddick AC, O'Donnell M, Harrison DJ, et al. Differential expression of prognostic proteomic markers in primary tumour, venous tumour thrombus and metastatic renal cell cancer tissue and correlation with patient outcome. PLoS One. 2013;8(4):e60483.

4. Escudier B, Albiges L, Sonpavde G. Optimal management of metastatic renal cell carcinoma: current status. Drugs. 2013;73(5):427-38.

5. Bustin SA, Benes V, Garson J, Hellemans J, Huggett J, Kubista M, et al. The need for transparency and good practices in the qPCR literature. Nat Methods. 2013;10(11):1063-7.

6. Jung M, Ramankulov A, Roigas J, Johannsen M, Ringsdorf M, Kristiansen $\mathrm{G}$, et al. In search of suitable reference genes for gene expression studies of human renal cell carcinoma by real-time PCR. BMC Mol Biol. 2007;8:47.

7. Vandesompele J, De Preter K, Pattyn F, Poppe B, Van Roy N, De Paepe A et al. Accurate normalization of real-time quantitative RTPCR data by geometric averaging of multiple internal control genes. Genome Biol. 2002; 3(7):RESEARCH0034.

8. Caradec J, Sirab N, Revaud D, Keumeugni C, Loric S. Is GAPDH a relevant housekeeping gene for normalisation in colorectal cancer experiments? Br J Cancer. 2010;103(9):1475-6.

9. Guo CM, Liu SQ, Sun MZ. Novel insight into the role of GAPDH playing in tumor. Clin Transl Oncol. 2013;15(3):167-72.

10. Bjerregaard H, Pedersen S, Kristensen SR, Marcussen N. Reference genes for gene expression analysis by real-time reverse transcription polymerase chain reaction of renal cell carcinoma. Diagn Mol Pathol. 2011;20(4):212-7.

11. Gresner SM, Golanska E, Kulczycka-Wojdala D, Jaskolski DJ, Papierz W, Liberski PP. Selection of reference genes for gene expression studies in astrocytomas. Anal Biochem. 2011;408(1):163-5.

12. Kılıc Y, Celebiler AC,, Sakızlı M. Selecting housekeeping genes as references for the normalization of quantitative PCR data in breast cancer. Clin Transl Oncol. 2013;16(2):184-190. doi:10.1007/ s12094-013-1058-57.

13. Krasnov GS, Oparina NY, Dmitriev AA, Kudryavtseva AV, Anedchenko EA, Kondrat'eva TT. RPN1, a new reference gene for quantitative data normalization in lung and kidney cancer. Mol Biol. 2011;45(2):211-20.

14. Ohl F, Jung M, Radonic A, Sachs M, Loening SA, Jung K. Identification and validation of suitable endogenous reference genes for gene expression studies of human bladder cancer. J Urol. 2006;175(5):1915-20.

15. RefFinder. http://www.leonxie.com/referencegene.php?type= reference. Accessed 20 Aug 2014.

16. Pfaffl MW, Tichopad A, Prgomet C, Neuvians TP. Determination of stable housekeeping genes, differentially regulated target genes and sample integrity: BestKeeper-Excel-based tool using pair-wise correlations. Biotechnol Lett. 2004;26(6):509-15.

17. Andersen CL, Jensen JL, Orntoft TF. Normalization of real-time quantitative reverse transcription-PCR data: a model-based variance estimation approach to identify genes suited for normalization, applied to bladder and colon cancer data sets. Cancer Res. 2004;64(15): $5245-50$.

18. Silver N, Best S, Jiang J, Thein SL. Selection of housekeeping genes for gene expression studies in human reticulocytes using real-time PCR. BMC Mol Biol. 2006;7:33.

19. (CHMP) CfMPfHU. Guideline on bioanalytical method validation. In: Agency EM, editor. London: European Medicines Agency; 2011. p. 1-22.

20. Bustin SA, Benes V, Garson JA, Hellemans J, Huggett J, Kubista M, et al. The MIQE guidelines: minimum information for publication of quantitative real-time PCR experiments. Clin Chem. 2009;55(4): 611-22.

21. Dijkstra JR, van Kempen LC, Nagtegaal ID, Bustin SA. Critical appraisal of quantitative PCR results in colorectal cancer research: can we rely on published qPCR results? Mol Oncol. 2014. doi:10. 1016/j.molonc.2013.12.016.

22. van Amsterdam P, Companjen A, Brudny-Kloeppel M, Golob M, Luedtke S, Timmerman P. The European Bioanalysis Forum community's evaluation, interpretation and implementation of the European Medicines Agency guideline on Bioanalytical Method Validation. Bioanalysis. 2013;5(6):645-59.

23. Caradec J, Sirab N, Keumeugni C, Moutereau S, Chimingqi M, Matar C, et al. 'Desperate house genes': the dramatic example of hypoxia. Br J Cancer. 2010;102(6):1037-43.

24. Noon AP, Vlatkovic N, Polanski R, Maguire M, Shawki H, Parsons K, et al. p53 and MDM2 in renal cell carcinoma: biomarkers for disease progression and future therapeutic targets? Cancer. 2010;116(4):780-90.

25. Warburton HE, Brady M, Vlatkovic N, Linehan WM, Parsons K, Boyd MT. p53 regulation and function in renal cell carcinoma. Cancer Res. 2005;65(15):6498-503.

26. Glenn ST, Jones CA, Liang P, Kaushik D, Gross KW, Kim HL. Expression profiling of archival renal tumors by quantitative PCR to validate prognostic markers. Biotechniques. 2007; 43(5):639-40, $42-3,47$.

27. Dupasquier S, Delmarcelle AS, Marbaix E, Cosyns JP, Courtoy PJ, Pierreux CE. Validation of housekeeping gene and impact on normalized gene expression in clear cell renal cell carcinoma: critical reassessment of YBX3/ZONAB/CSDA expression. BMC Mol Biol. 2014;15:9.

28. Wotschofsky Z, Meyer HA, Jung M, Fendler A, Wagner I, Stephan C, et al. Reference genes for the relative quantification of microRNAs in renal cell carcinomas and their metastases. Anal Biochem. 2011;417(2):233-41.

29. Gokmen-Polar Y, Cook RW, Goswami CP, Wilkinson J, Maetzold D, Stone JF, et al. A gene signature to determine metastatic behavior in thymomas. PLoS One. 2013;8(7):e66047.

30. Wierzbicki PM, Adrych K, Kartanowicz D, Dobrowolski S, Stanislawowski M, Chybicki J, et al. Fragile histidine triad (FHIT) gene is overexpressed in colorectal cancer. J Physiol Pharmacol. 2009;60 Suppl 4:63-70. 
31. Wierzbicki PM, Adrych K, Kartanowicz D, Stanislawowski M, Kowalczyk A, Godlewski J, et al. Underexpression of LATS1 TSG in colorectal cancer is associated with promoter hypermethylation. World J Gastroenterol. 2013;19(27):4363-73.

32. Nag S, Zhang X, Srivenugopal KS, Wang MH, Wang W, Zhang R. Targeting MDM2-p53 interaction for cancer therapy: are we there yet? Curr Med Chem. 2013;21(5):553-574.

33. Sun M, Shariat SF, Cheng C, Ficarra V, Murai M, Oudard S, et al. Prognostic factors and predictive models in renal cell carcinoma: a contemporary review. Eur Urol. 2011;60(4):644-61.

34. Shuch B, Linehan WM, Srinivasan R. Aerobic glycolysis: a novel target in kidney cancer. Expert Rev Anticancer Ther. 2013;13(6):711-9.

35. Zigeuner R, Ratschek M, Rehak P, Schips L, Langner C. Value of p53 as a prognostic marker in histologic subtypes of renal cell carcinoma: a systematic analysis of primary and metastatic tumor tissue. Urology. 2004;63(4):651-5.
36. De Block M, Debrouwer D. RNA-RNA in situ hybridization using digoxigenin-labeled probes: the use of high-molecular-weight polyvinyl alcohol in the alkaline phosphatase indoxyl-nitroblue tetrazolium reaction. Anal Biochem. 1993;215(1):86-9.

37. Zhang F, Wang ZM, Liu HY, Bai Y, Wei S, Li Y, et al. Application of RT-PCR in formalin-fixed and paraffin-embedded lung cancer tissues. Acta Pharmacol Sin. 2010;31(1):111-7.

38. Li YL, Ye F, Hu Y, Lu WG, Xie X. Identification of suitable reference genes for gene expression studies of human serous ovarian cancer by real-time polymerase chain reaction. Anal Biochem. 2009;394(1):110-6.

39. Gebhardt FM, Scott HA, Dodd PR. Housekeepers for accurate transcript expression analysis in Alzheimer's disease autopsy brain tissue. Alzheimers Dement. 2010;6(6):465-74.

40. Curtis KM, Gomez LA, Rios C, Garbayo E, Raval AP, Perez-Pinzon MA, et al. EF1alpha and RPL13a represent normalization genes suitable for RT-qPCR analysis of bone marrow derived mesenchymal stem cells. BMC Mol Biol. 2010;11:61. 